\title{
A Clinical Review on Huntington Disease
}

\author{
Pooja Malkani*, Prince Raj and Amit Singh \\ M. Pharm Research Scholar, Monad University, Uttar Pradesh
}

Submission: October 04, 2018; Published: November 28, 2018

*Corresponding author: Pooja Malkani, M. Pharm Research Scholar, School of Pharmacy, Monad University, Hapur, Uttar Pradesh, India

\begin{abstract}
Huntington disease (HD) is a progressive, fatal, neurodegenerative disorder caused by an expanded (Cytosine, Adenine, Guanine) CAG repeat in the huntingtin gene, which encodes an abnormally long polyglutamine repeat in huntingtin protein. HD is characterised by unwanted choreatic movements, behavioural and psychiatric disturbances and dementia. HD is an autosomal dominant inherited disease caused by an elongated CAG repeat (36 repeats or more) on the short arm of chromosome 4p16.3 in huntingtin gene. The longer the CAG repeat, and then the onset of disease is earlier.

The mechanism by which neuronal degeneration and cell death are being generated in HD may include excitotoxicity, energy deficit, oxidative stress, inflammatory process and protein aggregation. In the brain, the basal ganglia are highly affected which organize motor movement. The disease is characterised by a primary progressive loss of medium spiny projection neuron in basal ganglia. When the disease develops before age 20 , the condition is called juvenile HD. Management should be versatile and is based on treating symptoms with a view to improving quality of life. Medication and non-medical care for depression and aggressive behavior may be required.
\end{abstract}

Keywords: Huntington disease; Dementia; Neurodegeneration; oxidative stress; juvenile HD

Abbreviations: HD: Huntington disease, CAG: Cytosine Adenine Guanine, HTT: Huntingtin protein, MSN: Medium Spiny Neurons, TGase: Transglutaminase

\section{Introduction}

The first description of disease was given by waters in 1842 . But it was not until 1872, after the lecture and description of the disease by George Huntington, then it known as Huntington's chorea. It is a neurodegenerative disorder passing within families from generation to generation with onset in middle age and characterised by unwanted choreatic movements, behaviour, psychiatric disturbances and dementia [1]. Death occurs an average of 15 to 20 years after symptom first appear, with some patients dying earlier from falls or suicide and others surviving for 30 to 40 years. Clinically signs and symptoms usually begin between the ages of 35 and 50, with death typically following 1520 years later [2].

It is monogenic, fully penetrant and like other neurodegenerative diseases- a disorder of protein misfolding. HD is caused by CAG triplet repeat expansion in Huntingtin protein (HTT) which encodes an expanded polyglutamine stretch in HTT [3]. The disease is inherited in autosomal dominant manner with age dependant penetrance associated with nearly full penetrance by age 65 years [4]. Huntington disease causes movement disorders, cognitive deterioration and psychiatric disturbances. Symptoms begin insidiously, usually between the ages of 35 and 50, but the age of onset can vary from early childhood until old age. The disease is progressive and fatal some 15-20 years after symptom onset. In patients with juvenile-onset HD, the signs and symptoms are somewhat different; they include bradykinesia, rigidity and dystonia, and chorea can be completely absent.

Involuntary movements can take the form of tremor and affected children often develop epileptic seizures. HD is characterized by a striking specificity of neuronal loss. The most sensitive region is striatum, with about $57 \%$ loss of cross-sectional area from caudate nucleus and about $65 \%$ loss of the putamen in typical postmortem samples. There is also loss of neurons in the thalamus, substantia nigra and in the subthalamic nucleus. Cerebellar atrophy is most frequently reported in cases with juvenile onset disease [5]. The HD gene is located on chromosome 4 p16.3 and the genetic alteration which causes the disease is an increase of the no. of repetitions of three nucleic acids (C, A and G) in the coding region of the first axon of HD gene. This CAG "triplet" is normally repeated about 20 times, but an approximate doubling in the no. of repeats to 40 or more results in the expression of disease [6].

\section{Epidemiology}

Huntington disease is a rare neuropsychiatric disorder with a prevalence of $5-10$ per 100,000 in the Caucasian population [7]. HD has a prevalence of 10.6-13.7 individuals per 100,000 in western populations. Japan, Taiwan and Hong Kong have a much lower incidence of HD with a prevalence of 1-7 per million; in South Africa lower rates are seen in black populations compared to 
white and mixed populations. The difference in disease prevalence across ethnic groups relates to genetic differences in Htt gene [8]. The highest frequencies of HD are found in Europe and European countries. The lowest frequencies are documented in Africa, China, Japan, and Finland [9]. The generality in most European countries ranges from $1.63-9.95$ per 100,000 people. A study on the distribution of CAG repeats in normal population suggests a higher prevalence of HD in India closer to that seen in Western Europe. Based on the results, haplotype analysis suggested the presence of a founder mutation in a subset of families and provide evidences for multiple and geographically distinct origin for HD mutation in India [10].

\section{Neuropsychological and Clinical Description of Hd}

A broad range of symptoms portraying a chronically progressive course and fluctuating clinical picture are reported as neuropsychiatric features of HD. The characteristic behavioural changes in early stage HD including depression, irritability, mental inflexibility and apathy have been described as "choreopathy" [11].

\section{Motor Signs and Symptoms}

The characteristic motor changes are involuntary, unwanted movements. The movement disorder of HD consists of two components: involuntary movements and abnormal voluntary movements. Chorea consists of continuous and irregular jerky or writhing motions. The disordered voluntary movements observed in HD include: abnormal eye movements, hypometric saccades and catchy pursuit, uncoordinated, arrhythmic and slow fine motor movements, dysphagia and dysarthria, rigidity and gait disturbance [12]. Movement disturbance in HD can be split into a hyperkinetic phase with prominent choreain the early stages of disease, which then tends to plateau [13]. The hypokinetic phase is characterized by bradykinesia, dystonia, balance and gait disturbance. The hypokinetic movement disorders show association with disease duration and CAG length [14].

\section{Behaviour and Psychiatric Symptoms}

These signs and symptoms have a highly negative impact on functioning and on the family because of their impact on daily life. The most frequently occurring sign is depression. The diagnosis is difficult due to occurrence of weight loss, apathy and inactivity in HD. Suicide occurs more frequently in early symptomatic individuals and in premanifest gene carriers [15]. The most recent study from cohort includes both premanifest and manifest participants, shows that apathy is most common occurring in $28 \%$ while depression, irritability and obsessive compulsive behaviour occur in around 13\%. Psychosis is occurring in 1\% [16]. Apathy is related to disease condition whereas anxiety and depression are not. Psychosis may appear, mainly in later stages of disease. In most cases it goes together with cognitive decline. The clinical picture is comparable to schizophrenia with paranoid and acoustic hallucinations. In the early disease, hyper-sexuality can cause considerable problems in a relationship [11].

\section{Dementia}

Cognitive decline is the other main symptoms of HD. The term "cognitive" refers to tasks of the brain that involve knowing, thinking, remembering, organizing and judging [17]. Cognitive changes in HD may be due to distruption of striatal- frontal circuits [18].

\section{Cognitive Impairments Often Associated with HD Include}

a. Difficulty organizing, prioritizing or focusing on tasks.

b. Lack of flexibility or the tendency to get stuck on a thought, behaviour or action.

c. Lack of impulse control that can result in outbursts, acting without thinking and sexual promiscuity.

d. Lack of awareness of one's own behaviours and abilities.

e. Difficulty in learning new information.

\section{Secondary Symptoms and Signs}

An unintended weight loss has been reported in all patients. As more attention is now paid to this phenomenon, the loss seems to be a little less severe, the cause being diverse. Although it seems that chorea should play the main role in weight loss, it has been shown that there is no relation between weight loss and chorea or other movement disorders [19]. More practical issues, such as slower functioning, decreased appetite, difficulty handling food and swallowing certainly play a major role. But hypothalamic neuronal loss is also a causative factor [20].

\section{Pathogenesis}

Mutant huntingtin results in neuronal dysfunction and death through several mechanisms. These include direct effects from the exon 1 of Mhtt fragment, the propensity of Mhtt to form abnormal aggregates and its effects on cellular proteostasis, axonal transport, transcription and translation, mitochondrial and synaptic function [3]. Medium spiny neurons (MSNs) of the striatum are selectively vulnerable to the effects of Mhtt [21]. The cause for the selective vulnerability of indirect pathway MSNs is unclear; however, dopamine D2 receptors may be a factor as they are expressed by indirect but not direct MSNs and have been implicated in HD pathogenesis [22]. Other hypotheses include the loss of brain derived neurotrophic factor, glutamate excitotoxicity from cortico-striatal projections and toxic effects of repeat associated non-ATG translation proteins [23] (Figure 1).

HTT is a very large protein predicted to consist mainly of repeated units of about 50 amino acids, termed HEAT repeats. These repeats are composed of two antiparallel $\alpha$-helices with a helical hairpin configuration, which assemble into a superhelical structure with a continuous hydrophobic core [24]. Most available evidence-including dominant genetic transmission, presence of abnormal aggregated proteins, and findings of biochemical, cell and mouse model studies suggest that HD arises predominantly from gain of a toxic function from an abnormal conformation of mutant Htt. 


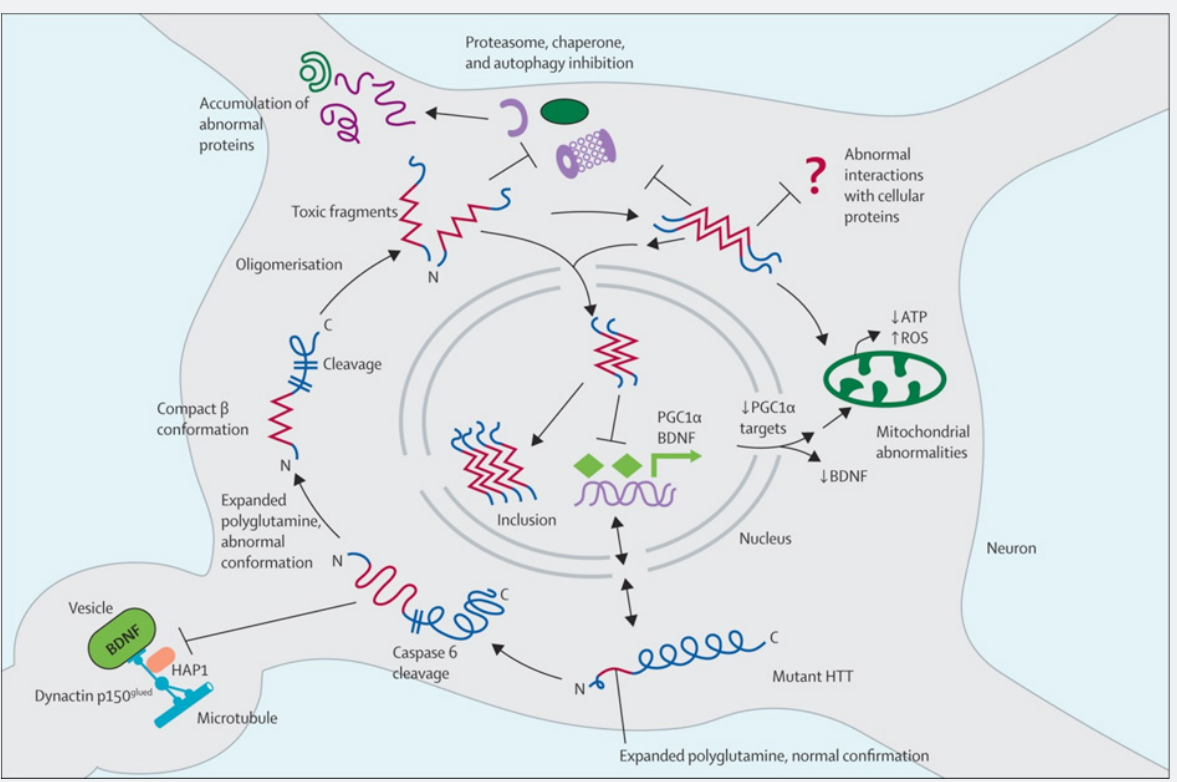

Figure 1: HTT is a very large protein predicted to consist mainly of repeated units of about 50 amino acids, termed HEAT repeats.

The RNA might also have toxic properties, and loss of function of $\mathrm{Htt}$ could also contribute to disease pathogenesis, perhaps entailing antisense RNA [25]. Key features of HD pathogenesis have been described. First, mutant Htt has the propensity to form abnormal confirmations, including $\beta$-sheet structures. Second, systems for handling abnormal proteins are impaired in cells and tissues from HD patients or models. Third, Htt is cut off and gives rise to toxic $\mathrm{N}$-terminal fragments. Fourth, post-translational modifications of Htt influence toxicity, via conformational changes, aggregation propensity, cellular localization, and clearance. Fifth, nuclear translocation of mutant Htt enhances toxic effects of the protein, in part via transcription related effects [26].

\section{Juvenile HD}

When the disease develops before age 20 , the condition is called juvenile HD. An earlier emergence of the disease often results in a somewhat different set of symptoms and faster disease progression [27]. Behaviour disturbances and learning difficulties at school are often the first signs. Motor behaviour is often hypokinetic and bradykinetic with dystonic components. In $75 \%$ of the juveniles the father is the affected parent [28].

\section{Disease Development}

The course of the life of a person with one parent with HD can be divided into at risk, a preclinical (A) and a clinical (B) stage. The clinical course is roughly divided into three parts indicating a decrease in independence and increase in the need for care. The clinical stage with clear manifest signs is preceded by the premanifest gene positive stage, and the transition phase, when more and more doubt about manifestations of signs emerges. During periods of stress, irrespective of whether this is physical or psychological, it is not uncommon for clinical signs to become manifest. These signs can fade away provisionally when the circumstances normalize. In the past, the first symptom was always a motor sign. Dependant on the family and doctor experience with the disease a diagnosis was suggested. However, over the last 20 years it has become clear [29] that psychiatric as well as cognitive changes can be the first signs, many years before motor signs become visible. If the non-motor signs are less specific, it can be very difficult to make a diagnosis. In retrospect, many patients mention a gradual change in behaviour and performance at work. They stayed home for sometimes with a burn-out or a depression [30].

\section{Management Including Treatment}

The most commonly used therapies in HD patients are symptomatic drug therapies and no therapies has been developed that effectively modifies disease progression. Even though the pathogenesis of HD has still not been resolved and a cure is not available, many therapeutic options are available for treating symptoms and signs with a view to improving quality of life. Treatment consists of drug prescription and non-medication advice [31].

\section{Dopamine Blocking Medications}

Abnormal movements in HD occur as a result of increased activity via the direct circuit and decreased activity via the indirect circuit, both mediated by dopamine. The atypical neuroleptic clozapine binds to dopamine receptors and blocks dopamine binding and subsequent signalling. When tested in a double-blind placebo controlled clinical trial [32]. Clozapine was only effective in reducing dyskinesias in patients that had no prior exposure to neuroleptics [33]. Tetrabenazine is a drug that is available clinically in many countries which acts by preventing the packaging of dopamine into vesicles, thereby suppressing its presymptomatic release [34]. It also prevents dopamine signalling by blocking postsynaptic dopamine receptors. Drowsiness, depressed mood, parkinsonism, and akathisia were the most commonly reported adverse effects. 


\section{Glutamate Antagonism- NMDA Receptor Antagonists}

Increase in glutamate release activate the NMDA receptors and increase the level of calcium and cause neurotoxicity. The drugs which block the NMDA receptors may be useful to decrease the symptoms of HD [35]. The moderate effectiveness of antidopaminergic therapies may be outweighed by debilitating side effects like Parkinsonism, tardative dyskinesias, and severe depression. It has been thought for some time that levodopainduced dyskinesias in Parkinson disease occur as a result of increased NMDA sensitivity and are reduced by treatment with NMDA receptor antagonist [36].

Multiple daily doses of amantadine were successful in reducing dyskinesias by upto $56 \%$. Memantine has also been tested in clinical trial for HD [33]. GABA mimetic drugs and GABA transminase inhibitors are also used in clinical trial for the treatment of HD [34]. Remacemide is a non-competitive NMDAreceptor antagonist. Patients receiving remacemide 200mg/ day dose showed an overall improvement in chorea level [37]. Riluzole is a glutamate release inhibitor. Two double-blind, placebo-controlled RCTs were found that investigate its effect on chorea in HD [38].

Cannabinoids receptor agonists: Cannabinoids receptors behave as neuromodulator in the brain, in a variety of processes, such as the regulation of motor behaviour, cognition, learning and antinociception. Cannabinoids receptors are destroyed in the basal ganglia [39]. Antioxidants: One component of excitotoxicity in HD is oxidative stress and antioxidants may therefore have therapeutic utility. A novel antioxidant, BN-82451 improved motor ability and survival and ameliorated neurodegeneration in R6/2 HD mice [40]. Neuroprotective agents: Fluoxetine, atomoxetine, and modafinil were effective in cognitive, behavioural and motor symptoms [41].

\section{Developing Novel Therapies}

Agents that inhibit mutant huntingtin aggregation: These agents inhibit mutant huntingtin from aggregation would provide a way to prevent the progression of the disease. These direct aggregation inhibitors have been tested in various HD models such as cell culture and transgenic HD mice [42]. Transglutaminase inhibitors: Transglutaminase (TGase) can use huntingtin as a substrate to cross-link huntingtin molecules. TGase provides an additional mechanism for the formation of aggregation of mutant huntingtin. It suggests that TGase plays a major role in HD pathogenesis [43]. Cystamine is an inhibitor of TGase showed a significant neuroprotective effect [44].

\section{Protease Inhibitors}

Huntingtin can be cleaved by proteases, including Caspase, calpain, and aspartyl protease. Caspase and calpain-mediated partial cleavage of mutant huntingtin promotes huntingtin aggregation and cellular toxicity, inhibitors of huntingtin partial cleavage might have therapeutic value [45]. Neuroprotective approaches: Coenzyme Q10 Targeting enzymes or cofactors that play a role in energy production could help to reduce cell death. CoenzymeQ10 is a molecule in the electron transport chain that carries electrons from complex I and II to complex III [46]. Coenzyme Q10 reduces formation of reactive oxidative species and oxidative stress.

\section{Creatine}

Creatine has been hypothesized to be effective as a therapy for HD because it is capable of buffering ATP levels in cells. When creatine is ingested it is converted into phosphocreatine and stored. In the face of an energy deficit, phosphocreatine can donate its phosphate to ADP in the presence of creatinekinase, producing the high energy ATP molecule. Creatine has been shown to be effective in diminishing motor and cognitive symptoms in the 3-NP toxin induced rat model of HD [47].

\section{References}

1. Ross AC Raymund (2010) Huntington's disease: a clinical review. Ross Orphanet Journal of Rare Diseases 5: 40.

2. S Vivek, S Priety, D Rahul (2012) Huntington's disease: Clinical complexities and Therapeutic strategies. Journal of Advanced scientific research 3(2): 30-36.

3. CA Ross, SJ Tabrizi (2011) Huntington's disease: from molecular pathogenesis to clinical treatment. Lancet Neurol 10(1): 83-98.

4. Langbehn DR, Brinkman RR, Falush D, Paulsen JS, Hayden MR (2004) On behalf of an international Huntington's Disease Collaborative Group. A new model for prediction of the age of onset and penetrance for Huntington's disease based on CAG length. Clin Genet 65:267-77.

5. RC David (2002) Lessons from animal models of Huntington's disease. Trends in Genetics 18(4): 202-209.

6. MH Richard (2004) Huntington's disease Genetics. The Journal of the American Society for Experimental NeuroTherapetics 1(2): 255-262.

7. Bates G, Harper P, Jones L (2002) Huntington's disease. Oxford University press, Oxford.

8. Bates GP, Dorsey R, Gusella JF (2015) Huntington disease. Nat Rev Dis Primers 1: 1-21.

9. Conneally PM. Am J Hum Genet (1984) Huntington disease: genetics and epidemiology 36:506-526.

10. Murgod UA, Saleem Q, Anand A, Brahmachari SK (2001) A clinical study of patients with genetically confirmed Huntington's disease from India. J Neurol Sci 190(1-2): 73-78.

11.Van Duijn E, Kingma EM, Vander Mast RC (2007) Psychopathology in Verified Huntington's Disease Gene Carriers. The Journal of Neuropsychiatry and clinical Neurosciences 19(4): 441-448.

12. Penney JB, Young AB, Shoulson I (1990) Huntington's disease in Venezuela: 7 years of follow-up on symptomatic and asymptomatic individuals. Mov Disord 5(2): 93-99.

13. Dorsey ER, Beck CA, Darwin K (2013) Natural history of Huntington disease. JAMA Neurol 70(12): 1520-1530.

14. Rosenblatt A, Liang KY, Zhou H (2006) The association of CAG repeat length with clinical progression in Huntington disease. Neurology 66(7): 1016-1020.

15. Wheelock VL, Tempkin T, Marder K, Nance M (2003) Neurology 60(6): 998-1001

16. Van Duijn E, Craufurd D, Hubers AA (2014) Neuropsychiatric symptoms in a European Huntington's disease cohort (REGISTRY). J Neurol Neurosurg Psychiatry 85(12): 1411-1418. 
17. Brandt J, Strauss ME (1986) Attempt at preclinical identification of Huntington's disease using the WAIS. J Clin Exp Neuropsychol 8(3): 210-218.

18. Butters N, Sax D, Montgomery K, Tarlow S (1978) Comparison of the neuropsychological deficits associated with early and advanced Huntington's disease. Arch Neurol 35(9): 585-589

19. Aziz NA, van der Burg JM, Landwehrmeyer GB, Brudin P, Stijnen T (2008) Weight loss in Huntington disease increases with higher CAG repeat number. Neurology 71(19): 1506-1513.

20. Kremer HP, Roos RA, Dingjan GM, Bots GT, Bruyn GW (1991) The hypothalamic lateral tuberal nucleus and the characteristics of neuronal loss in Huntington's disease. Neurosci Lett 132(1): 101-104.

21. Bates GP, Dorsey R, Gusella JF (2015) Huntington disease. Nat Rev Dis Primers 1:15005.

22. Plotkin JL, Surmeier DJ (2015) Corticostriatal synaptic adaptations in Huntington's disease. Curr Opin Neurobiol 33: 53-62.

23. Deyts C, Galan-Rodriguez B, Martin E (2009) Dopamine D2 receptor stimulation potentiates Poly-Q-Huntington-induced mouse straital neuron dysfunctions via Rho/ROCK-II activation. PLoS One 4(12): e8287.

24. Li W, Serpell LC, Carter WJ, Rubinsztein DC, Huntington JA (2006) Expression and characterization of full-length human huntingtin, an elongated HEAT repeat protein. J Biol Chem 281(23):15916-15922.

25. Shao J, Diamond MI (2007) Polyglutamine diseases: emerging concepts in pathogenesis and therapy. Hum Mol Genet 16(2): R115-123

26. Tobin AJ, Signer ER (2000) Huntington's disease: the challenge for cell biologists. Trends cell Biol 10(12): 531-36.

27. Mayoclinic

28. Quarrell OWJ, Brewer HM, Squiteri F, Barker RA, Nance MA (2014) Landwehrmeyer B: Juvenile Huntington's disease.

29. Witjes-Ane MN, Vegter-van der Vlis M, van Vugt JP, Lanser JB, Hermans J, et al. (2003) Cognitive and motor functioning in gene carriers for Huntington disease: a baseline study. J Neuropsychiatry Clin Neurosci 15(1): 7-16.

30. Shoulson I, Fahn S (1979) Huntington disease: clinical care and evaluation. Neurology 29(1): 1-3.

31. Shilpa Ramaswamy, Kathleen M, Shannon, Jeffrey H Kordower (2007) Huntington's Disease: Pathological Mechanisms and Therapeutic Strategies. Cell Transplantation 16(3): 301-312.

32. Van VugtJ P, Siesling S, Vergeer M, vander Velde, EA Ross (1997) RA] Neurol. Neurosurg. Psychiatry 63: 35-39.
33. Bonelli MR, Gregor KW, Kapfhammer PH (2004) International Clinical Psychopharmacology 19: 51-62.

34. Ondo W G, Tintner R, Thomas M, Jankovic (2002) Tetrabenazine treatment for Huntington's disease-associated chorea. J. Clin. Neuropharmacol 25(6): 300-302.

35. Huntington Study Group (2006) Tetrabenazine as antichorea therapy in Huntington disease: a randomized controlled trial. Neurology $66: 366-372$

36. Calon F, Rajput AH, Hornykiewicz O, Bedard PJ, Di Paolo T (2003) Levodopa-induced motor complications are associated with alterations of glutamate receptors in Parkinson's disease. Neurobiol Dis 14(3): 404-416.

37. Huntington study group (2001) A randomized, placebo-controlled trial of coenzyme Q10 and remacemide in Huntington disease. Neurology 57(3): 397-404

38. GB Landwehrmeyer, B Dubois, B Kremer, PH Kraus (2007) Riluzole in Huntington disease: a 3-year randomized controlled study. Ann Neurol 62(3): 262-272.

39. Becker LI, Miguel RD, Ruzi JJF (2003) Current Drug Targets-CNS \& Neurological Disorders.

40. Hannan J (2004) I Drugs 7: 351-358.

41. AD Blackwell, NS Paterson, RA Barker (2008) The effects of modafinil on mood and cognition in Huntington disease, Psychopharmacology 199(1): 29-36.

42. Aiken CT, Tobin AJ, Schweiter ES (2004) A cell-based screen for drugs to treat Huntington's disease. Neurobiol Dis 16(3): 546-555.

43. Qin ZH, Wang J, Zhen LGU (2005) Acta Pharmacologica Sinica 26: 129142.

44. Karpuj MV, Becher MW, Springer JE, Chabas D (2002) Prolonged survival and decreased abnormal movements in transgenic model of Huntington disease, with administration of the transglutaminase inhibitor cystamine. Nat Med 8(2): 143-149.

45. Chen M, Ona VO, Li M, Ferrante RJ (2000) Minocycline inhibits caspase-1 and caspase- 3 expression and delays mortality in a transgenic mouse model of Huntington disease. Nat Med 6(7): 797-801

46. Kidd PM (2005) Altern. Med. Rev 10:268-293.

47. Harris RC, Soderlund K, Hultman E (1992) Elevation of creatine in resting and exercised muscle of normal subjects by creatine supplementation. Clin. Sci (Lond) 83(3): 367-374.

\section{Your next submission with Juniper Publishers} will reach you the below assets

- Quality Editorial service

- Swift Peer Review

- Reprints availability

- E-prints Service

- Manuscript Podcast for convenient understanding

- Global attainment for your research

- Manuscript accessibility in different formats

( Pdf, E-pub, Full Text, Audio)

- Unceasing customer service

Track the below URL for one-step submission https://juniperpublishers.com/online-submission.php 